\title{
Epidemioclinical and Progressive Aspects of the Adult Hemorrhagic Stroke in Bangui
}

\section{Emmanuel Yangatimbi ${ }^{1,2 *}$, Junior Koma Zobanga², Symphorien Shansy Grégbia², Josué Kinima², Pascal Mbelesso ${ }^{1,2}$}

${ }^{1}$ Department of Neurology, University Hospital of the Sino-Central African Friendship, Bangui, Central African Republic ${ }^{2}$ Faculty of Health Sciences, University of Bangui, Bangui, Central African Republic

Email: ${ }^{\star} y a n g \_e m m a 1 @ y a h o o . f r$

How to cite this paper: Yangatimbi, E., Zobanga, J.K., Grégbia, S.S., Kinima, J. and Mbelesso, P. (2020) Epidemioclinical and Progressive Aspects of the Adult Hemorrhagic Stroke in Bangui. Neuroscience \& Medicine, 11, 74-82.

https://doi.org/10.4236/nm.2020.113009

Received: July 13, 2020

Accepted: September 8, 2020

Published: September 11, 2020

Copyright ( 2020 by author(s) and Scientific Research Publishing Inc. This work is licensed under the Creative Commons Attribution International License (CC BY 4.0).

http://creativecommons.org/licenses/by/4.0/

(c) (i) Open Access

\begin{abstract}
Introduction: Hemorrhagic strokes in the elderly constitute a diagnostic and therapeutic emergency and, by their frequency and severity, determine a public health problem. Goal of the Study: To elucidate knowledge and make our contribution to the study of this pathology (describe the epidemioclinical and evolutionary aspects of hemorrhagic cerebrovascular accidents in adults in Bangui). Methodology: It was a retrospective study with descriptive and analytical aims covering a period of two years (2) from January 2017 to December 2018, conducted in the Neurology department of the Sino-Central African Friendship University Hospital. Results: During the study, 255 patients were hospitalized for stroke, including 20 cases of AVCH, representing a hospital frequency of $7.8 \%$. The average age was 60.05 years with extremes ranging from 50 to 78 years. The most represented age group was that of 50 to 60 years with a sex-ratio $(\mathrm{M} / \mathrm{F})$ of 1.2. Civil servants were more represented (35\%) followed by housewives (25\%). Alcohol was the main risk factor (95\%) followed by hypertension (80\%) and tobacco (40\%). Most of the patients (75\%) were admitted to the care facilities before 6 am (75\%). Lethality was $35 \%$. There was a significant statistical link between the Glasgow score and death $(\mathrm{p}=0.007)$. In this series, $75 \%$ of the cases had sequelae dominated by hemiparesis (75\%) and aphasia (25\%). Conclusion: First study in the Central African Republic, with a high frequency, shows that the AVCH of the elderly poses a public health problem. Requires great mass awareness in order to reduce its mortality rate.
\end{abstract}

\section{Keywords}

Epidemiology, AVCH, Elderly, Central African Republic 


\section{Introduction}

Cerebrovascular accident (stroke) is defined as the rapid development of localized or global clinical signs of brain dysfunction with no apparent cause other than a vascular origin that can lead to death. It therefore constitutes a diagnostic and therapeutic emergency and represents a public health problem [1] [2]. According to the literature, stroke is the second leading cause of death in the world and in developing countries (developing countries), behind cardiovascular diseases, ahead of infectious diseases, in particular pulmonary or diarrheal infections, tuberculosis, the Syndrome acquired immunodeficiency (AIDS) or malaria [3].

Hemorrhagic forms constitute $15 \%$ of strokes. They represent the rupture of a blood vessel within the cerebral parenchyma, the ventricles or the spaces under arachnoid. Arterial hypertension (hypertension) is the most important risk factor and cohort studies show that one in two strokes is seen in a hypertensive patient [4] [5]. Stroke affects all age groups with a predilection for the elderly [6]. Considering the aging of the world population by 2050 with a tripling of the number of people aged over 60 and a fourth of those aged 80 , there is almost a strong increase in the prevalence of stroke during of the century [7]. There are many epidemioclinical factors for hemorrhagic stroke that influences the prognosis in the elderly and few studies have highlighted the prognostic factors specific to the elderly after stroke. A study was carried out in Bangui at the University Hospital Center of the Sino-Central African Friendship (CHUASC) on epidemiological aspects in 2004 [8]. However, we do not have data on hemorrhagic stroke in the elderly in the Central African Republic. To do this, it seemed appropriate to us to carry out this work in order to elucidate knowledge and also to make our contribution to the study of this pathology.

\section{Methodology}

It was a retrospective study with descriptive and analytical aims. Our study took place over a period of two years (2) from January 2017 to December 2018. It consisted of all the patients hospitalized in the neurology department of the CHU of the Sino-Central African Friendship of Bangui for Hemorrhagic Stroke who met the inclusion criteria during the study period. Subjects of both sexes, over the age of 50, with suspected signs of hemorrhagic stroke and having complete records were included. All patients under the age of 50 with incomplete and unusable records were not included in the study.

The data were collected from the patient's paper files on pre-established survey cards and included the socio-demographic characteristics (sex, marital status, profession, Provenance); History (hypertension, diabetes, sickle cell anemia, HIV/AIDS, oral contraception, tobacco); Clinical signs (general condition of patients, data from the neurological clinical examination, data from the cardiovascular clinical examination); paraclinical signs (blood filth assessments, morphological examinations in cardiology) and progress under treatment. The data were 
entered by Word, Excel and analyzed with Epi info 6. The chi-square test was used to compare proportions with significance at $5 \%$.

\section{Results}

During this study, we collected 255 files of patients of any age suspected of having a stroke, including 20 cases of $\mathrm{AVCH}$ in subjects over 50 years of age, representing a hospital frequency of $7.8 \%$. The most represented age group was that of 50 to 60 years. The average age was 60.05 years with extremes ranging from 50 to 78 years with a ratio (M/F) of 1.2 (see Table 1 ). Public servants (35\%) were most affected followed by housewives $25 \%$, and the majority of the study population was single $(80 \%)$. In this series, $80 \%$ of cases had consulted the emergency room before being hospitalized, while $75 \%$ had consulted in the first six hours of the accident.

In terms of history, alcoholism was the most common risk factor (FDR) (95\%), followed by hypertension (80\%) and smoking (40\%), while familial ATCD was dominated by l' HTA and diabetes (25\%).

Clinically, the main reasons for hospitalizations were motor and sensory deficits $(100 \%)$ followed by headache (95\%), language impairment $(90 \%)$, and $80.0 \%$ of the cases had an impaired general condition. In this study, the majority of patients $(100 \%)$ had elevated hypertension, followed by temporo-spatial disorientation (95\%) and hemiplegia (95\%) (see Table 2), while 55\% of the cases had a Glasgow score lower than or equal to 7.

Paraclinically, $57.1 \%$ of the cases had left ventricular enlargement and $80 \%$ of our patients had a hypertensive etiology followed by the toxic etiology (15\%).

Evolutionarily, $60 \%$ of our patients had a hospital stay of less than a month. Out of 13 patients discharged from the hospital, $84.6 \%$ of cases had hemiparesis-like sequelae. In our series, Lethality was 35\%, and occurred within three weeks of hospitalization, especially in subjects with a disturbed state of alertness $(\mathrm{p}=0.007)$ (see Table 3$)$.

Table 1. Distribution of patients by sex and age.

\begin{tabular}{ccc}
\hline Age & \multicolumn{2}{c}{ Sex } \\
\cline { 2 - 3 } & Male & Female \\
\hline $24-29$ & 0 & 2 \\
$30-34$ & 1 & 1 \\
$35-39$ & 3 & 2 \\
$40-44$ & 7 & 1 \\
$45-49$ & 4 & 5 \\
Total & 15 & 11 \\
\hline
\end{tabular}


Table 2. Distribution of patients according to the main neurological physical signs.

\begin{tabular}{ccc}
\hline Main physical neurological signs & Number & $(\%)$ \\
\hline Cranial nerve abnormalities & 6 & 23.1 \\
Hemiplegia/hemiparesis & 26 & 100 \\
dysarthria & 2 & 7.7 \\
Aphasia & 7 & 26.9 \\
Cerebellar syndrome & 3 & 11.5 \\
Pyramidal syndrome & 26 & 100 \\
Time-space disorientation & 1 & 3.8 \\
Altered consciousness & 5 & 19.2 \\
\hline
\end{tabular}

Table 3. Analysis of physical neurological signs predicting the type of stroke.

\begin{tabular}{|c|c|c|c|c|}
\hline Determinants & AVCI & $\mathrm{AVCH}$ & $\mathrm{RC}$ et IC & $\mathrm{p}$ \\
\hline Cranial nerve abnormality & & & & 0.35 \\
\hline Yes & 4 & 2 & $0.68[0.09-6.67]$ & \\
\hline No & 15 & 5 & 1 & \\
\hline Hemiplegia & & & & 0.05 \\
\hline Yes & 6 & 5 & $0.20[0.02-1.31]$ & \\
\hline No & 13 & 2 & 1 & \\
\hline Hemiparesis & & & & 0.05 \\
\hline Yes & 13 & 2 & $5.04[0.76-46.89]$ & \\
\hline No & 6 & 5 & 1 & \\
\hline Aphasia & & & & 0.16 \\
\hline Yes & 4 & 3 & $0.37[0.05-2.72]$ & \\
\hline No & 15 & 4 & 1 & \\
\hline Pyramidal Syndrome & & & & 0.09 \\
\hline Yes & 14 & 7 & undetermined & \\
\hline No & 5 & 0 & & \\
\hline Cerebellar Syndrome & & & & 0.19 \\
\hline Yes & 3 & 0 & undetermined & \\
\hline No & 16 & 7 & & \\
\hline Impairment of consciousness & & & & 0.01 \\
\hline Yes & 3 & 5 & $0.09[0.01-0.64]$ & \\
\hline No & 16 & 2 & 1 & \\
\hline
\end{tabular}




\section{Discussion}

During our study, the hospital frequency was $7.8 \%$. This result can be superimposed on that found in Morocco [9], and lower than those found in Dakar and Madagascar [10] [11]. This difference could be related to the size of our sample and the absence of cerebral imagery which would have allowed us to make a good differential diagnosis with ischemic strokes.

The average age was $60.05+/-9.08$ years with extremes ranging from 50 to 78 years. Our result is identical to that found in Baltimore [12] with an average age of 60.09 years and superimposable on that found in Dakar [13]. However, several authors agree that the average age is different in different countries and, in general, hemorrhagic stroke affects patients around the age of 50 [10] [11] [14].

Men and women were equally affected with a sex ratio (M/F) of 1.2. According to literature data, AVCH usually affects male patients [15]. However, some authors report a female predominance [11] [16]. Civil servants (35\%), housewives (25\%), and retirees (20\%) were the most affected. This result is similar to that found in a study carried out in 2008 in Madagascar [11], where the unemployed were the most affected (44.10\%). This type of population was made up of retired patients, housewives and people who exercise fewer activities is a factor favoring the onset of $\mathrm{AVCH}$ [17]. Men and women were equally affected with sex. ratio $(\mathrm{M} / \mathrm{F})$ of 1.2. According to literature data, AVCH usually affects male patients [15]. However, some authors report a female predominance [11] [16].

During this series, $80 \%$ of the cases came from the emergency departments of the CHU. This result is identical to that found in Madagascar [11]. This would be logical, since our study was carried out in Bangui, capital of the Central African Republic (CAR) and many of our patients use non-medical means of transport that can worsen the patient's condition. The main reasons for hospitalization were sensory-motor disorders (100\%), headache (95\%) followed by language impairment (90\%). Our result corroborates the data of certain authors [9] [10].

Regarding the history, $95 \%$ of our patients were ethyl, $80 \%$ of known hypertensives and $40 \%$ of smokers. These data corroborate the data in the literature, which confirms on the one hand hypertension as the main risk factor for $\mathrm{AVCH}$, and on the other hand tobacco and alcohol as toxic substances which favor the appearance of AVCH [18] [19].

Physically, 95\% of our patients had hypertension (100\%), hemiparesis (95\%) followed by temporospatial disorientation (95\%). These results agree with data from different authors [20] [21] [22]. The majority of our patients (55\%) had a Glasgow score of less than 7. This result can be superimposed on that reported in Madagascar [11] which was $47.03 \%$.

On the paraclinical level, On 7 cases which carried out the electrocardiogram (ECG) one found an HVG (57.1\%); HVD (14.3\%); HAG (14.3\%) and normal in $14.3 \%$ of cases. These main disorders found were the same observed in Dakar in Senegal [23]. 
Etiologically, chronic hypertension was the main etiological factor (85\%). This result corroborates the data in the literature [16] [23]. In our study we did not find etiologies of malformation, tumor origins because the etiological diagnosis of this condition is made by imagery that we do not yet have in our country in this 21 st century.

In our series, $75 \%$ of cases consulted within the first six hours. Our result can be superimposed on that found in Madagascar [11]. Management within 6 hours of the accident improves the patient's prognosis according to the literature [24]. Lethality was $35 \%$ of cases. This result can be superimposed on those of certain African countries [10] [25] [26]. Whereas studies done in Europe [27] [28] show the mortality rate between 1.5 and $8 \%$. This mortality rate, higher in African series than European, reflects the flaws in treatment, in particular the late consultation period, the difficult management of co-morbidities (impaired consciousness, renal failure, etc.), the absence of public channels for medical transfer to specialized services and the absence of early and adequate care in our countries.

Most of the patients died with a hospital stay between 0 - 20 days and an admission time between $0-6 \mathrm{~h}$, but this lethality was not related to the hospital stay $(\mathrm{p}=0.44)$, nor with the admission deadline $(\mathrm{p}=0.78)$. Thus, the data in the literature have shown that treatment within 6 hours of the accident improves the patient's prognosis [24]. In our series, 6 patients died on chronic hypertension ( $p$ $=0.64$ ). High blood pressure was not statistically significant at the origin of the death. This result is similar to the results reported by some authors in Africa [11] [24].

In this study, 6 patients died with a Glasgow score of $8-13$. We found that this mortality was significantly correlated with the disturbance of the state of consciousness $(p=0.007)$. Our result is similar to the studies carried out in Dakar [13] [29] which confirmed that in general comatose strokes and in particular AVCH have a poor prognosis (82.9\%). The main sequelae were hemiparesis (75\%) and aphasia (25\%), respectively. Our data are superior to that found in Madagascar [11], where only $32.35 \%$ of patients have left intensive care with neurological sequelae (hemiplegia, dysarthria, memory loss, etc.). This could be explained by a lack of human and material resources in the field of functionality and rehabilitation in our country. However, as our work is not a follow-up study, we have not noticed any cases of dementia. Because it has been described in the literature that the recurrence of stroke is very often accompanied by sequelae of the type of dementia [30].

\section{Conclusions}

Hemorrhagic stroke in the elderly has proven to be a public health problem in Bangui. Its early mortality remains very significant but it also exposes to high neuropsychic sequelae in the short and medium term. The lack of a scanner has been very detrimental in our work because the diagnosis of certainty in this 21 st century is based only on brain imagery which does not yet exist in the country. 
The mortality associated with this condition remains higher and reflects the flaws in the precise diagnosis and adequate management. Hence the importance of optimizing support through training for all actors involved in the circuit from the central level (CHU) including those at the front line (health centers) through the implementation of protocols standardized care, better control of referral circuits in a specialized environment and above all awareness of the populations on vascular risk factors and their consequences, as well as on the warning signs of a stroke.

\section{Conflicts of Interest}

The authors declare no conflicts of interest regarding the publication of this paper.

\section{References}

[1] Béjot, Y., Touzé, E., Jacquin, A., Giroud, M. and Mas, J.L. (2009) Epidemiology of Stroke. MedSci, 25, 727-732. https://doi.org/10.1051/medsci/2009258-9727

[2] Hankey, G.J. and Warlow, C. (1999) Treatment and Second Prevention of Stroke: Evidence, Cost and Effect on Indiduals and Population. The Lancet, 354, 1457-1463. https://doi.org/10.1016/S0140-6736(99)04407-4

[3] Sagui, E. (2007) Les accidents vasculaires cérébraux en Afrique Sub saharienne. Médecine Tropicale, 67, 596-600.

[4] Yao, K.H., Sanogo, S., Binan, A., Hue Lou, A. and Diallo, A.D. (2011) Hypertension artérielle de novo compliqué de l'adulte au milieu hospitalier noir africain. Revue Internationale des Sciences Médicales, 13, 33-36.

[5] Rancurel, G. and Manai, R. (2005) Les accidents ischémiques transitoires du sujet âgé: Nouvelle définition et difficultés du diagnostic. Psychologies \& Neuropsychiatries du Vieillissement, 3, 17-26.

[6] Béjot, Y., Rouaud, O., Gentil, A., Caillier, M., Manckoundia. P., Pfitzenmeyer, P., Ossuby, G.V., Moreau, T. and Giroud, M. (2008) Les accidents vasculaires cérébraux du sujet âgé: Ce que nous a appris d'épidémiologie du sujet jeune. Revue Neurologique, 164, 809-814. https://doi.org/10.1016/j.neurol.2008.07.015

[7] Dabilgou, A.A., Adeline Kyelem, J.M., Dravé, A. and Nikièma Tanguy, M.I. (2018) Les accidents vasculaires cérébraux chez le sujet agé en milieu tropical: Aspects épidemiologiques, cliniques et facteurs pronostiques. Neurologie-Psychiatrie-Gériatrie, 18, 133-139.https://doi.org/10.1016/j.npg.2018.01.002

[8] Mbelesso, P., Tabo, A., Seboulo, P.C., Yangatimbi, E., Kette, C.G. and Senekian, V.P. (2007) Aspects épidémiologiques des accidents vasculaires cérébraux à l'hôpital de l'Amitié à Bangui en RCA. Benin Medical, 44, 44-46.

[9] Qureshi, A.I., Tuhrim, S., Brederick, J.P., Batier, H. and Hideki, D. (2001) Spontaneous Intracerebral Hemorrhage. The New England Journal of Medicine, 344, 1450-1460. https://doi.org/10.1056/NEJM200105103441907

[10] Touré, K., Thiam, A., Sène Diouf, F., Ndiaye, M., Coumé, M., Seck, L.B., Diagne, N.S., Diop, M.S., et al. (2008) Epidemiology of Stroke at the Clinic of Neurology, Fann University Teaching Hospital. Dakar Medical, 53, 105-110.

[11] Raveloson, N.E., Zodaly, N., Rakoto Arivony, S.T., Mbolamena, R.L. and Randriamiarana, J.M. (2011) Aspects épidemiocliniques, évolutifs et tomodensimetriques 
des accidents vasculaires cérébraux hémorragiques (34). Revue d Anesthésie-Réanimation et de Médecine d' Urgence, 3, 15-19.

[12] Wu, D., Gu, Z.W., Song, D.G., Liu, J.S., Gang, Z. and Tu, C.J. (2018) Développement et validation des modèles de pronostic d'hémorragie intracérébrale hypertensive. Médecine (Baltimore), 97, e12446. https://doi.org/10.1097/MD.0000000000012446

[13] Bandzouzi, P.E., Adjaratou, D.S., Dadoli, S.L.M., Ndiaye, M., Diop, A.G. and Ndiaye, M.M. (2016) Aspects épidemiocliniques, évolutifs et paraclinique de l'accident vasculaire cérébral du sujet âgé. Revue Neurologique, 172, A72. https://doi.org/10.1016/j.neurol.2016.01.171

[14] Zia, E., Hedbad, B., Pessah-Rasmen, H., Bergland, G., Janzon, L. and Engstrom, G. (2007) Blood Pressure in Relation to the Incidence of Cerebral Infraction and Intracerebral Hemorrhage. Hupertensive Haemorrhage: Debated Nomenclature Is Still Relevant. Stroke, 38, 2681-2685. https://doi.org/10.1161/STROKEAHA.106.479725

[15] Grillo, P., Velly, L. and Bruder, N. (2006) Accident vasculaire cérébrale hémorragique: nouveautés sur la prise en charge. Annales Françaises d Anesthésie et de Réanimation, 25, 868-873. https://doi.org/10.1016/j.annfar.2006.03.030

[16] Honnart, D. and Fournier, C. (2007) AVC hémorragique: Etiologie, critères de gravité et de pronostic. Urgences, 267-278.

[17] Radak, Z., Kumagai, S. and Taylor, A.W. (2007) Effects of Exercise on Brain Function: Role of Free Radicals. Applied Physiology, Nutrition, and Metabolism, 947-953.

[18] Davis, S.M., Broderick, J., Hennerici, M., Brun, N.C., Diringer, M.N. and Mayer, S.A. (2006) Hematoma Growth Is a Determinant of Mortality and Poor Outcome after Intracerebral Hemorrhage. Neurology, 66, 1175-1181. https://doi.org/10.1212/01.wnl.0000208408.98482.99

[19] Gill, J.S., Shipley, M.J., Tsementzis, S.A., Homby, R.S., Gill, S.K. and Hitchcock, E.R. (1991) Alcohol Consumption-A Risk Factor for Hemorrhagic and Non-Hemorrhagic Stroke. The American Journal of Medicine, 90, 489-497. https://doi.org/10.1016/0002-9343(91)90610-A

[20] Ohwakik, K., Yana, E., Nagashima, H., Hirata, M., Nakagoni, T. and Tomura, A. (2004) Blood Pressure Management in Acute Intracerebral Hemorrhage: Relationship between Elevated Blood Pressure and Hematoma Enlargement. Stroke, 35, 1364-1367. https://doi.org/10.1161/01.STR.0000128795.38283.4b

[21] Leira, R., Dovalos, A., Silva, V., Ge-Penala, A., Tejada, J. and Gracia, M. (2004) Early Neurologic Deterioration in Intracerebral Hemorrhage: Predictors and Associated Factors. Neurology, 63, 461-467. https://doi.org/10.1212/01.WNL.0000133204.81153.AC

[22] Dieynabou Sow, A. and Touré, K. (2016) Pronostic des hémorragies cérébrales spontanées du sujet de moins de 55 ans, dans un pays en développement d'Afrique de l'Ouest Exemple du Sénégal, à propos de cinquante-trois cas. Médecine et Santé Tropicales, 26, 170-174.

[23] Toure, K., Kane, A., Taldia, A., Ndiaye, M.M. and Ndiaye, I.P. (2010) Apport de la tomodensitométrie dans l'épidémiologie des accidents vasculaires cérébraux à l'hôpital général de Grand Yoff. Médecine d Afrique Noire, 57, 455-460.

[24] Cowppli-bony, F., Sonan-Douayoma, T., Akani, F., Ahogo, C., N'guessan, K. and Beurgre, E.K. (2007) Epidémiologie des accidents vasculaires hémorragiques au service de Neurologie à Bouaké. Médecine d’ Afrique Noire, 54, 199-202. 
[25] Keita, A.D., Touré, M. and Diawara, A. (2005) Aspects épidémiologiques des AVC dans le service de tomodensitométrie à l'hôpital du point $\mathrm{G}$ à Bamako, Mali. Médecine Tropicale, 65, 453-457.

[26] Feigin, V.L., Lawes, C.M., Bennett, D.A. and Anderson, C.S. (2003) Stroke Epidemiology: A Review of Population-Based Studies of Incidence, Prevalence, and Case Fatality in the Late 20th Century. The Lancet Neurology, 2, 43-53.

https://doi.org/10.1016/S1474-4422(03)00266-7

[27] Bogousslavsky, J. (1990) Les accidents vasculaires cérébraux du sujet jeune. Medicine and Hygiene, 48, 2750-2754.

[28] Ruiz-sandoval, J.L. and Cantu, C. (1999) Intra Cerebral Haemorrhage in Young People: Analysis of Risk Factors, Location, Causes and Prognosis. Stroke, 30, 537-541. https://doi.org/10.1161/01.STR.30.3.537

[29] Sene-Diouf, F., Mapoure, N.Y. and Ndiaye, M. (2008) Survie des accidents vasculaires cérébraux comateux à Dakar Sénégal. Revue Neurologique, 164, 452-458. https://doi.org/10.1016/j.neurol.2008.01.007

[30] Leys, D., Hénon, H., Mackowiak-Cordolin, M.A. and Pasquier, F. (2005) Poststroke dementeia. The Lancet Neurology, 4, 752-759.

https://doi.org/10.1016/S1474-4422(05)70221-0 